\title{
Direct in vitro Regeneration of Gerbera (Gerbera jamesonii Bolus)
}

\author{
C.L. Vijayalakshmi ${ }^{1}$, P. Babu ${ }^{2}$, A.N. Bagali ${ }^{1}$, C.D. Soregaon ${ }^{3}$ and \\ Ashwini H. Wadageri ${ }^{1}$ \\ ${ }^{1}$ Department of Horticulture, ${ }^{3}$ Department of Genetics and Plant Breeding, College of \\ Agriculture, Vijayapur, ${ }^{2}$ Department of Horticulture, College of Agriculture, Hanumanamatti, \\ University of Agricultural Sciences, Dharwad - 580 005, Karnataka, India \\ *Corresponding author
}

\section{A B S T R A C T}

\section{Keywords}

Gerbera jamesonii, sterilization, BAP (6-benzyl amino purine), IAA (indole-3-acetic acid)

Article Info

Accepted:

17 December 2018

Available Online:

10 January 2019
Gerbera (Gerbera jamesonii Bolus) seeds were used as primary source of explants for sterilization. Seeds were sterilized with $0.1 \%$ mercuric chloride for 2 minutes to obtain minimum contamination (10\%). MS (Murashige and Skoog's media) supplemented with $4 \mathrm{mg}$ per litre BAP + $0.3 \mathrm{mg}$ per litre IAA served as the best medium for shoot proliferation from in vitro shoots as it produced maximum number of shoots (2.67) with maximum number of leaves (4.73) and maximum shoot length $(1.92 \mathrm{~cm})$ at three weeks of inoculation. For root regeneration MS media supplemented with $2 \mathrm{mg}$ per litre IBA was recorded as the best rooting media as regenerated roots early (10.87) with maximum number of roots (4.73) and maximum root length $(3.47 \mathrm{~cm})$.

\section{Introduction}

Gerbera is one of the leading cut flowers and ranks fifth among the top ten cut flowers of the world (Parthasarathy and Nagaraju, 1999). The genus Gerbera was named in honour of a German naturalist Traugott Gerber, who travelled in Russia in 1743. The genus consists of about forty species (Das and Singh, 1989). Out of the recorded species, only one species Gerbera jamesonii is under cultivation. Gerbera belongs to the family Asteraceae and can be propagated by both sexual and asexual methods. Most of the commercially grown cultivars are propagated through vegetative means so as to maintain uniformity, genetic purity and quality flower production (Peper et al., 1971). Among the vegetative means, multiplication through division of clumps is the most common method used for several decades. Gerbera can also be propagated through cuttings. However, the multiplication by these methods is too slow to be commercially practicable. Many new varieties are released nowadays, for commercialization of those varieties, planting material is required 
on large scale, which requires the development of an easier, quicker and economically viable method of propagation with no or less contamination. Tissue culture finds its tremendous application in ornamental crops especially in areas of propagation and crop improvement.

Plant propagation either through meristems or non-meristems culture enables production of large number of plants in short span of time in limited space. This method enables a million fold expansions per year of a desired plant in addition to get disease free, healthy and vigorous planting material (Murashige et al., 1974). Ajithkumar et al., (2013) reported that the leaves of gerbera were collected and disinfected with pril and bavistin $(0.1 \mathrm{~g} / 100$ $\mathrm{ml}$ ) for about 10 minutes. The leaves were washed in sterilized water until the detergent gets washed out. Under aseptic conditions, leaves were sterilized with 0.1 per cent $\mathrm{HgCl}_{2}$ for 5 minutes and washed thoroughly with sterilized water to remove sterilants. Shylaja et al., (2014) obtained a highly efficient micropropagation protocol for commercial multiplication of gerbera with unopened flower buds as explants where culture establishment and propagule multiplication in MS medium supplemented with BAP $3 \mathrm{mg}$ per litre + NAA $0.1 \mathrm{mg}$ per litre was found good and for root morphogenesis, MS medium supplemented with IBA $1 \mathrm{mg}$ per litre was found effective with more number of roots and longer roots. In general, the vegetative explants sources from the field had high contamination rates and slow culture growth due to harsh sterilization of explants with chemicals, which damage the growing points. Therefore, mature seeds were used for establishment of gerbera tissue culture so that clean cultures can easily be obtained from the seeds. The objective of this study is (1) To standardise the protocol for sterilization of explants (2) To study the influence of hormones on shoot and root regeneration.

\section{Materials and Methods}

The present investigation was carried out at the Plant Tissue Culture laboratory in the Department of Biotechnology, College of Agriculture, Vijayapur, University of Agricultural Sciences, Dharwad during the year 2017-2018.

\section{Chemicals and other media ingredients}

All the chemicals required for media preparation were of analytical grade, procured from Hi-media and LOBA Chemi companies. Sucrose, a source of carbon, was obtained from Hi-media Limited. Agar-agar (Bacteriological agar) was used throughout the research work as a gelling agent, also procured from Hi-media.

\section{Glassware}

All glassware used during the course of experiment like culture bottles, culture tubes, beakers, pipettes and funnels were procured from M/s. Borosil India Limited, Mumbai.

Glassware were soaked in potassium dichromate solution for six hours followed by a thorough washing in a set of tap water in order to completely remove all traces of dichromate solution and further soaked in a detergent solution (Teepol $0.1 \%$ ) overnight and then thoroughly washed in tap water and rinsed twice in double distilled water. The glassware were then dried in forced air draft oven at $100^{\circ} \mathrm{C}$ and stored in dustproof areas until used.

\section{Tools and equipments}

The chemicals used to prepare Murashige and Skoog's medium was weighed individually using a digital electronic balance (Shimadzu). Elico magnetic stirrer with hot Plate was used to adjust the $\mathrm{pH}$ of media and to melt the agar 
during preparation of media. Throughout the investigation double distilled water was used and it was collected from quartz double distillation unit. Media bottles and tools like forceps, scalpels etc., were sterilised by using table-top vertical autoclave. All the aseptic manipulations for micropropagation studies were carried out in double chambered laminar air flow.

\section{Preparation of explant}

Murashige and Skoog's medium (MS) (1962) at full strength was used for the present investigation. Different plant growth regulators (PGRs) like indole-3-acetic acid (IAA) and 6-benzyl amino purine (BAP), $\alpha-$ Naphthalene acetic acid (NAA) and Indole-3byteric acid (IBA) were added at various concentrations to MS medium and the $\mathrm{pH}$ of the medium was adjusted to 5.6- 5.8. Media was autoclaved at $1.5 \mathrm{Kgcm}^{-2}$ and $121^{\circ} \mathrm{C}$ for $15 \mathrm{~min}$. All the aseptic manipulations like surface sterilization, preparation and inoculation of explants were carried out in the laboratory using laminar air flow cabinet. Seeds of gerbera which are flat and pointed were taken in a beaker containing water and only those seeds sunken were used for sterilisation. Seeds were washed in tap water for five minutes and then washed in sterilized distilled water in laminar air flow for five minutes and treated with tween 20 for 10 minutes. Then the seeds were washed thoroughly in double distilled water and treated with bavistin $(0.1 \%)$ for fifteen minutes and washed again with double distilled water to remove traces of bavistin. Then the seeds were treated with 2 per cent sodium hypochlorite, 70 per cent alcohol and 0.1 per cent mercuric chloride for different period according to the treatments. After treating the seeds with sterilants, they were kept on the autoclaved tissue paper, closed with the same and allowed to dry to remove moisture from the surface to minimize the contamination. After drying, the seeds were placed vertically on MS media supplemented with different concentrations of BAP and IAA for shoot proliferation and lids of the bottles were closed. Forceps and scalpels were dipped in the alcohol and heated as and when necessary to minimize the spread of contamination from one to another explants. In this experiment, different levels of BAP (2, 4, 6, 8 and $10 \mathrm{ppm}$ ) alone and in combination with IAA $(0.1, \quad 0.2, \quad 0.3 \quad \mathrm{ppm})$ were supplemented to MS medium to study the influence on shoot regeneration. The inoculated bottles were kept in growth chamber and allowed to grow under the temperature of about $25 \pm 2^{0} \mathrm{C}$ with $70-80$ per cent relative humidity and the photoperiod of 16 hours light and 8 hours dark for shoot initiation. The in vitro micro shoots placed on the fresh medium (NAA and IBA) for root regeneration. After inoculation, data on sterilization was recorded at 20 days of inoculation, shoot regeneration was recorded at three weeks of inoculation and root regeneration was recorded at four weeks of inoculation. Observations on cultures were carried out every day. The data collected from the experimental results were subjected to statistical analysis by adopting the completely randomised design as described by Panse and Sukhatme (1986).

\section{Results and Discussion}

\section{Effect of sterilants on contamination}

To obtain aseptic cultures, seeds were treated with different surface sterilants viz., sodium hypochlorite (2\%), alcohol $(70 \%)$ and mercuric chloride $(0.1 \%)$ were cultured on MS medium supplemented with different growth regulators (BAP and IAA). There was significant difference in contamination among the treatments and it is evident from data as presented in Table 1. Among the various treatments, none of the treatment could 
generate contamination free culture. However, surface sterilization with mercuric chloride $(0.1 \%)$ for 2 minutes found to be the best with least contamination (10\%) (Fig. 2). While, the maximum contamination (75\%) observed when the explants were surface sterilized with 70 per cent alcohol for 30 seconds (Fig. 1). However, if the duration of the treatment with 70 per cent alcohol increased, the rate of contamination reduced significantly. Contamination mostly from moulds was registered followed by fungi, bacteria and yeast.

Influence of hormones (BAP, BAP + IAA) on shoot regeneration

In this experiment, different levels of BAP (2, $4,6,8$ and $10 \mathrm{ppm}$ ) alone and in combination with IAA $(0.1,0.2, \quad 0.3 \quad \mathrm{ppm})$ were supplemented to MS medium to study the influence on shoot regeneration. The observation on number of days taken for shoot regeneration was recorded from the date of inoculation, number of shoots per clump; number of leaves per shoot and shoot length were recorded three weeks after inoculation and presented in Table 2.

The data on number of days taken for shoot initiation was significantly differed with the hormonal concentrations (Table 2). Early shoot initiation was recorded in treatment MS supplemented with BAP at $4 \mathrm{ppm}+$ IAA at $0.3 \mathrm{ppm}$ (12.13 days); it was followed by BAP at $4 \mathrm{ppm}+$ IAA at $0.2 \mathrm{ppm}$ (15.87 days), which was on par with BAP at $4 \mathrm{ppm}$. The delay in shoot initiation was observed in media with MS alone (21.20 days), followed by MS supplemented with high concentration of both BAP and IAA (18.60 days). It is evident from the table 2 that, maximum number of shoots per clump was observed when MS supplemented with BAP at $4 \mathrm{ppm}+$ IAA at $0.3 \mathrm{ppm}$ (2.67), followed by BAP at 4 ppm + IAA at $0.2 \mathrm{ppm}$ (2.30), which was on par with BAP at 4 ppm (2.27), while, minimum number of shoots per clump was recorded with control (0.67), at three weeks of inoculation. With increase in the concentration of BAP, the number of shoots initiated was reduced at three and six weeks after inoculation. The variations in hormones and their concentrations resulted significant differences for the number of leaves produced per shoot. The number of leaves per shoot observed at three weeks after inoculation were highest with the treatment BAP at $4 \mathrm{ppm}+$ IAA at $0.3 \mathrm{ppm}$ (4.73), followed by BAP at 4 ppm (4.33). However, minimum number of shoots per clump was recorded with control (1.13), followed by MS supplemented with higher concentrations of BAP (10 ppm and 10 $\mathrm{ppm})$ and IAA (0.1 ppm and $0.2 \mathrm{ppm}$ respectively i.e. 2.07) (Table 2). The differences in shoot length due to influence of hormone and their concentration were significant. Maximum shoot length was obtained when MS media supplemented with $\mathrm{BAP}$ at $4 \mathrm{ppm}+\mathrm{IAA} 0.3 \mathrm{ppm}(1.92 \mathrm{~cm})($ Fig. $3)$ when compared to rest of the treatments. Next to this BAP alone at $4 \mathrm{ppm}(1.71 \mathrm{~cm})$ registered higher shoot length, which was on par with BAP at $4 \mathrm{ppm}+$ IAA at $0.2 \mathrm{ppm}$ $(1.61 \mathrm{~cm})$ and BAP at $4 \mathrm{ppm}+$ IAA at 0.1 ppm $(1.61 \mathrm{~cm})$. While, it was minimum with $\mathrm{BAP}$ at $10 \mathrm{ppm}+\mathrm{IAA}$ at $0.2 \mathrm{ppm}(0.81 \mathrm{~cm})$ (Fig. 4) followed by control $(0.83 \mathrm{~cm})$, at three weeks of inoculation.

\section{Influence of hormones (NAA and IBA) on root regeneration}

In this experiment, elongated shoots from the previous experiment were subjected to different sources of auxins like NAA and IBA at different concentrations to determine the best source and concentration of auxin for root initiation. The data regarding the influence of auxins on number of roots per shoot and length of the roots was collected after four weeks of incubation while, number of days for 
rooting from the date of inoculation and the results are presented in Table 3.

The rooting hormones, NAA and IBA showed significant differences with respect to number of days taken for root initiation. Hormonal concentrations also effected significantly with respect to number of days taken for root initiation. The data given in the table 3 revealed that MS medium containing $2 \mathrm{ppm}$ IBA rooted early (10.87) followed by MS with 2 ppm NAA (12.20); MS with 1.5 ppm NAA and 3 ppm IBA (13.60); and last to root was in control (21.47 days). There were significant differences with respect to number of roots produced among the treatments. The maximum roots were produced with MS medium supplemented with 2 ppm IBA (4.73), followed by MS with 2 ppm NAA (4.33) and 3 ppm IBA (3.87). The treatment that produced minimum number of roots was observed with basal MS with no supplementation of hormones (1.47), followed by MS medium with 0.5 ppm NAA (2.33) (Table 3). The auxin treatments showed significant differences in respect of root length. The media containing $2 \mathrm{ppm}$ IBA produced longest root $(3.47 \mathrm{~cm})$ (Fig. 5), followed by media with 2 ppm NAA (3.11 $\mathrm{cm}$ ); while, shortest root length was observed obviously, with the control $(0.95 \mathrm{~cm})$ (Fig. 6), followed by MS media containing $0.5 \mathrm{ppm}$ NAA $(2.21 \mathrm{~cm})$. Best quality root type having long and thick roots was observed with MS media supplemented with 2 ppm IBA (3.47) (Table 3).

\section{Sterilization}

Most of the microorganisms, bacteria and fungi in particular are generally confined to the outer surface of the plants grown in the external environment. These contaminants compete adversely for nutrients with plant material growing in vitro. Therefore, as for as possible, explants must be free from all microbial contaminants when they are placed on nutrient medium. It is therefore, now very clear that all tissue culture material should be free of pathogens especially when it is a matter of exchange or export to different nations of the world. Various surface sterilization strategies have been tailored according to varied morphology of the explants in order to achieve desirable level of culture asepsis in gerbera. Aseptic culture is the primary objective in any worthwhile in vitro programme. However, strength of sterilant combinations has to be standardized to achieve a desired level of asepsis.

To obtain aseptic cultures, explants were treated with three different surface sterilants, viz., $\mathrm{NaOCl}(2 \%)$, ethanol $(70 \%)$ and $\mathrm{HgCl}_{2}$ $(0.1 \%)$, of these; surface sterilization with mercuric chloride $(0.1 \%)$ for 2 minutes was found to be the best with least contamination $(10 \%)$. The difference between the treatments with respect to duration of mercuric chloride underlines the importance of optimum time duration required (2 min.) for surface sterilization under laminar flow hood. Similar observation was made by Mandal et al., (2002), reported that 0.1 per cent $\mathrm{HgCl}_{2}$ (for 2 minutes) was best surface sterilant for gerbera. This is because the most useful radical in $\mathrm{HgCl}_{2}$ is probably the chloride, commonly present as bichloride of mercury. Mercuric chloride is extremely poisonous due to high bleaching action of two chloride atoms and also mercuric ions, which combines strongly with protein causing death of the organism (Pauling, 1955).

\section{Shooting}

In the present investigation on shoot regeneration, in vitro gerbera shoots took least number of days for shoot regeneration in MS media supplemented with BAP at $4 \mathrm{ppm}$ in combination with IAA at $0.3 \mathrm{ppm}$. With the same treatment combination, maximum 
number of shoots per clump, number of leaves per shoot and shoot length was also observed at three weeks of inoculation.

Growth and morphogenesis in vitro are regulated by the interaction and balance between growth regulators supplied in the medium and growth substances produced endogenously by the cultured cells. Apart from the direct effect on cellular mechanisms, many synthetic growth regulators may in fact modify the level of endogenous substances. Addition of auxins together with cytokinin becomes essential for shoot induction and multiplication depending on the plant type. The right combination of auxin and cytokinin in the culture medium determined the effectiveness of micropropagation of gerbera. Addition of strong auxin with BAP promoted better shoot formation compared to weak auxin (Pierik et al., 1973). Cytokinin alone in the medium induces the formation of micro shoots. Combination of auxins and cytokinins induces the formation of adventitious shoots and roots. The role of auxins and cytokinin in micropropagation is well known and the best morphogenetic response can be obtained from synergistic effect of compatible auxins and cytokinin combination (Aswath and Choudhary, 2001).

The observations in parallel to this outcome were made by Nazari et al., (2014), where highest number of shoots per explants was observed in the MS medium containing 0.1 mg per litre IAA $+4 \mathrm{mg}$ per litre $\mathrm{BA}+1 \mathrm{mg}$ per litre TDZ. Similarly, Aswath and Survey (2004) obtained more number of shoots with $3.0 \mathrm{mg}$ per litre BAP and $0.5 \mathrm{mg}$ per litre IAA concentrations in gerbera selection GJ-23. Shailaja et al., (2004) as well, stated BAP (3 $\mathrm{mg} / \mathrm{l})$ was the best growth hormone for obtaining maximum shoots per explant in gerbera. Various combinations of auxins and cytokinins have also been tried to achieve multiple shoot induction in gerbera (Barbosa et al., 1993). Among the cytokinins, BAP was found to be a better cytokinin for shoot proliferation in gerbera (Hempel et al., 1985).

Table.1 Standardization of explants sterilization

\begin{tabular}{|c|c|c|c|}
\hline Treatments & $\begin{array}{c}\text { No. of explants } \\
\text { used }\end{array}$ & $\begin{array}{c}\text { No. of explants } \\
\text { contaminated }\end{array}$ & $\begin{array}{c}\text { Per cent } \\
\text { contamination (\%) }\end{array}$ \\
\hline $\mathrm{T}_{1}$ & 20 & 10 & 50 \\
\hline $\mathrm{T}_{2}$ & 20 & 5 & 25 \\
\hline $\mathrm{T}_{3}$ & 20 & 7 & 35 \\
\hline $\mathrm{T}_{4}$ & 20 & 15 & 75 \\
\hline $\mathrm{T}_{5}$ & 20 & 8 & 40 \\
\hline $\mathrm{T}_{6}$ & 20 & 6 & 30 \\
\hline $\mathrm{T}_{7}$ & 20 & 10 & 50 \\
\hline $\mathrm{T}_{8}$ & 20 & 2 & 10 \\
\hline $\mathrm{T}_{9}$ & 20 & 5 & 25 \\
\hline
\end{tabular}

$\mathrm{T}_{1}$ - Sodium hypochlorite $2 \%$ for $10 \mathrm{~min} ; \mathrm{T}_{2}$-Sodium hypochlorite $2 \%$ for $20 \mathrm{~min} ; \mathrm{T}_{3}$-Sodium hypochlorite $2 \%$ for $30 \mathrm{~min} ; \mathrm{T}_{4}$-Alcohol $70 \%$ for $30 \mathrm{sec} ; \mathrm{T}_{5}$-Alcohol $70 \%$ for $60 \mathrm{sec} ; \mathrm{T}_{6}-$ Alcohol $70 \%$ for $120 \mathrm{sec} ; \mathrm{T}_{7}-\mathrm{HgCl}_{2} 0.1 \%$ for $1 \mathrm{~min} ; \mathrm{T}_{8}-\mathrm{HgCl}_{2} 0.1 \%$ for $2 \mathrm{~min} ; \mathrm{T}_{9}-\mathrm{HgCl}_{2} 0.1 \%$ for $3 \mathrm{~min}$ 
Table.2 Influence of hormones (BAP and BAP+ IAA) on shoot regeneration 3 weeks after inoculation

\begin{tabular}{|c|c|c|c|}
\hline Treatments & $\begin{array}{l}\text { No. of shoots/ } \\
\text { clump }\end{array}$ & $\begin{array}{l}\text { No. of leaves/ } \\
\text { shoot }\end{array}$ & $\begin{array}{l}\text { Shoot length } \\
\text { (cm) }\end{array}$ \\
\hline $\mathbf{T}_{0}$ & 0.67 & 1.13 & 0.83 \\
\hline $\mathbf{T}_{1}$ & 1.73 & 3.67 & 1.32 \\
\hline $\mathbf{T}_{2}$ & 2.27 & 4.33 & 1.71 \\
\hline$T_{3}$ & 1.53 & 3.27 & 1.30 \\
\hline $\mathbf{T}_{4}$ & 1.33 & 2.87 & 1.22 \\
\hline $\mathbf{T}_{5}$ & 1.13 & 2.47 & 1.01 \\
\hline$T_{6}$ & 2.07 & 3.47 & 1.39 \\
\hline $\mathbf{T}_{7}$ & 2.07 & 3.93 & 1.61 \\
\hline $\mathbf{T}_{8}$ & 1.73 & 3.27 & 1.27 \\
\hline $\mathbf{T}_{9}$ & 1.47 & 2.47 & 1.09 \\
\hline $\mathbf{T}_{10}$ & 1.20 & 2.07 & 0.87 \\
\hline$T_{11}$ & 2.13 & 3.73 & 1.31 \\
\hline$T_{12}$ & 2.30 & 4.13 & 1.61 \\
\hline $\mathbf{T}_{13}$ & 1.67 & 3.40 & 1.29 \\
\hline$T_{14}$ & 1.40 & 2.53 & 1.05 \\
\hline $\mathbf{T}_{15}$ & 1.27 & 2.07 & 0.81 \\
\hline $\mathbf{T}_{16}$ & 1.93 & 3.73 & 1.53 \\
\hline $\mathbf{T}_{17}$ & 2.67 & 4.73 & 1.92 \\
\hline $\mathbf{T}_{18}$ & 1.67 & 2.73 & 1.19 \\
\hline$T_{19}$ & 1.47 & 2.60 & 1.03 \\
\hline $\mathbf{T}_{20}$ & 1.27 & 2.13 & 0.89 \\
\hline S.Em. \pm & 0.040 & 0.077 & 0.026 \\
\hline C.D at $5 \%$ & 0.114 & 0.220 & 0.075 \\
\hline C.D at $1 \%$ & 0.152 & 0.294 & 0.101 \\
\hline
\end{tabular}

$\mathrm{T}_{0}$ - Control $; \mathrm{T}_{1}-\mathrm{BAP}$ at $2.0 \mathrm{mg}$ per litre $; \mathrm{T}_{2}-\mathrm{BAP}$ at $4.0 \mathrm{mg}$ per litre; $\mathrm{T}_{3}-\mathrm{BAP}$ at $6.0 \mathrm{mg}$ per litre $; \mathrm{T}_{4}$ - BAP at $8.0 \mathrm{mg}$ per litre $; \mathrm{T}_{5}-\mathrm{BAP}$ at $10.0 \mathrm{mg}$ per litre; $\mathrm{T}_{6}-\mathrm{BAP}$ at $2.0 \mathrm{mg}$ per litre + IAA $0.1 \mathrm{mg}$ per litre; $\mathrm{T}_{7}-\mathrm{BAP}$ at $4.0 \mathrm{mg}$ per litre + IAA $0.1 \mathrm{mg}$ per litre; $\mathrm{T}_{8}-\mathrm{BAP}$ at $6.0 \mathrm{mg}$ per litre + IAA $0.1 \mathrm{mg}$ per litre; $\mathrm{T}_{9}-\mathrm{BAP}$ at $8.0 \mathrm{mg}$ per litre + IAA $0.1 \mathrm{mg}$ per litre; $\mathrm{T}_{10}-\mathrm{BAP}$ at $10.0 \mathrm{mg}$ per litre + IAA $0.1 \mathrm{mg}$ per litre; $\mathrm{T}_{11}$ - BAP at $2.0 \mathrm{mg}$ per litre + IAA $0.2 \mathrm{mg}$ per litre; $\mathrm{T}_{12}-\mathrm{BAP}$ at $4.0 \mathrm{mg}$ per litre + IAA $0.2 \mathrm{mg}$ per litre; $\mathrm{T}_{13}-\mathrm{BAP}$ at $6.0 \mathrm{mg}$ per litre + IAA $0.2 \mathrm{mg}$ per litre; $\mathrm{T}_{14}-\mathrm{BAP}$ at $8.0 \mathrm{mg}$ per litre + IAA $0.2 \mathrm{mg}$ per litre; $\mathrm{T}_{15}-\mathrm{BAP}$ at $10.0 \mathrm{mg}$ per litre + IAA $0.2 \mathrm{mg}$ per litre; $\mathrm{T}_{16}$ $\mathrm{BAP}$ at $2.0 \mathrm{mg}$ per litre + IAA $0.3 \mathrm{mg}$ per litre; $\mathrm{T}_{17}-\mathrm{BAP}$ at $4.0 \mathrm{mg}$ per litre + IAA $0.3 \mathrm{mg}$ per litre; $\mathrm{T}_{18}-\mathrm{BAP}$ at 6.0 mg per litre + IAA $0.3 \mathrm{mg}$ per litre; $\mathrm{T}_{19}-\mathrm{BAP}$ at $8.0 \mathrm{mg}$ per litre + IAA $0.3 \mathrm{mg}$ per litre; $\mathrm{T}_{20}-\mathrm{BAP}$ at $10.0 \mathrm{mg}$ per litre + IAA $0.3 \mathrm{mg}$ per litre

Fig.1\&2 Maximum contamination from moulds with $70 \%$ alcohol for 30 seconds \& Contamination free Gerbera culture
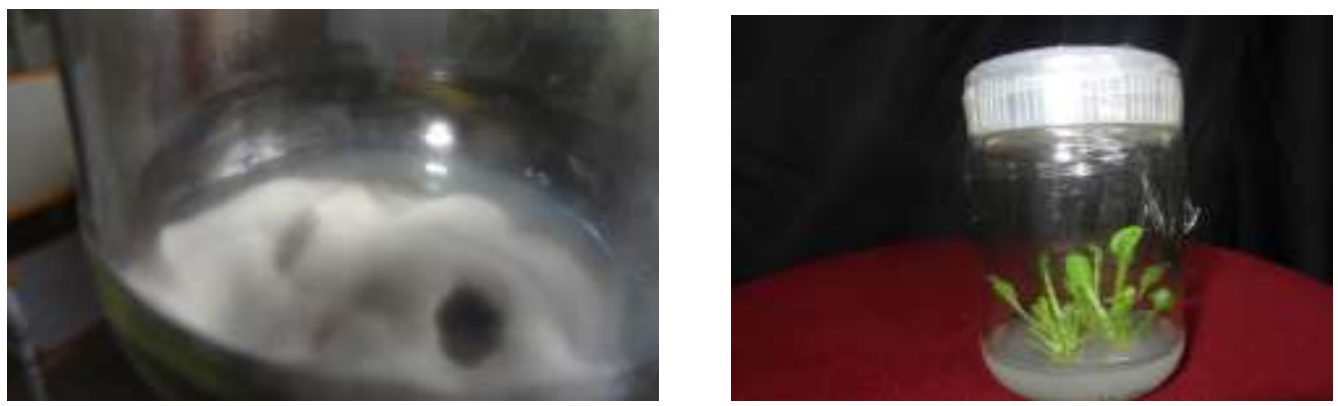
Table.3 Influence of hormones (NAA and IBA) on root regeneration

\begin{tabular}{|c|c|c|c|}
\hline Treatments & $\begin{array}{c}\text { No. of days for } \\
\text { rooting }\end{array}$ & No. of roots/ shoot & Root length (cm) \\
\hline $\mathbf{T}_{\mathbf{0}}$ & 21.47 & 1.47 & 0.95 \\
\hline $\mathbf{T}_{\mathbf{1}}$ & 17.13 & 2.33 & 2.21 \\
\hline $\mathbf{T}_{\mathbf{2}}$ & 15.60 & 3.47 & 2.38 \\
\hline $\mathbf{T}_{\mathbf{3}}$ & 13.60 & 3.73 & 2.66 \\
\hline $\mathbf{T}_{\mathbf{4}}$ & 12.20 & 4.33 & 3.11 \\
\hline $\mathbf{T}_{\mathbf{5}}$ & 13.67 & 3.47 & 2.89 \\
\hline $\mathbf{T}_{\mathbf{6}}$ & 10.87 & 4.73 & 3.47 \\
\hline $\mathbf{T}_{\mathbf{7}}$ & 13.60 & 3.87 & 3.04 \\
\hline S.Em. $\mathbf{\pm}$ & 0.175 & 0.067 & 0.046 \\
\hline C.D at 5 \% & 0.524 & 0.200 & 0.137 \\
\hline C.D at 1 \% & 0.722 & 0.275 & 0.189 \\
\hline
\end{tabular}

Culture period 4 weeks

$\mathrm{T}_{0}$ - Control; $\mathrm{T}_{1}$ - NAA $0.5 \mathrm{mg}$ per litre; $\mathrm{T}_{2}$ - NAA $1.0 \mathrm{mg}$ per litre; $\mathrm{T}_{3}$ - NAA $1.5 \mathrm{mg}$ per litre; $\mathrm{T}_{4}$ - NAA $2.0 \mathrm{mg}$ per litre; $\mathrm{T}_{5}$ - IBA $1.0 \mathrm{mg}$ per litre; $\mathrm{T}_{6}$ - IBA $2.0 \mathrm{mg}$ per litre; $\mathrm{T}_{7}$ - IBA $3.0 \mathrm{mg}$ per litre

Fig.3\&4 Maximum shoot length with BAP at $4 \mathrm{mg}$ per litre + IAA at $0.3 \mathrm{mg}$ per litre 3 weeks of inoculation \& Minimum shoot length with control 3 weeks after inoculation
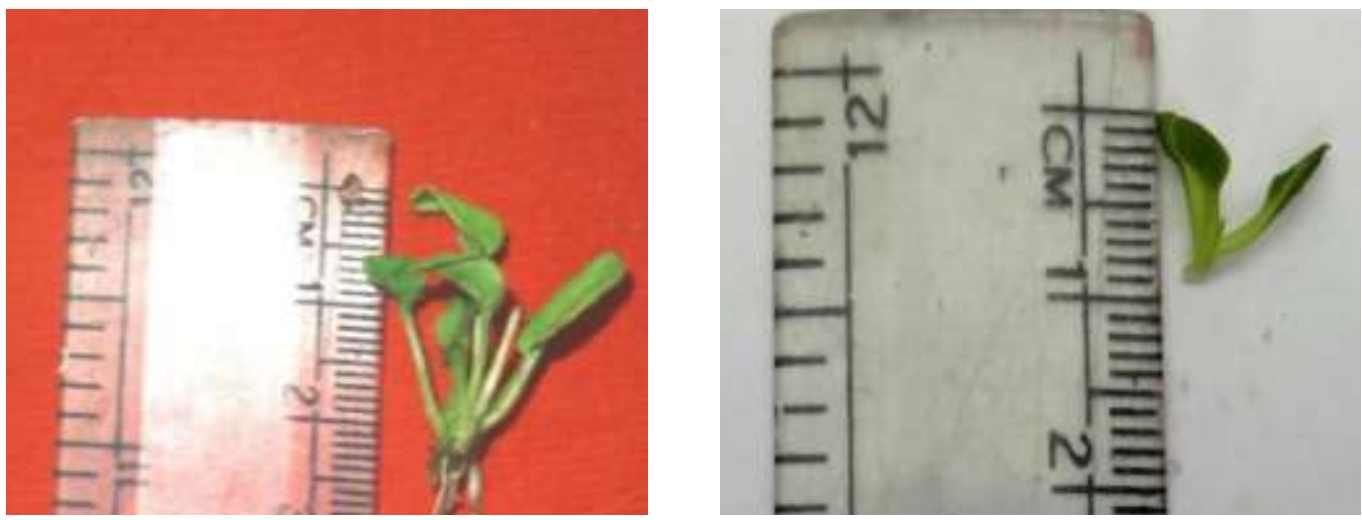

Fig.5\&6 Maximum root length observed with IBA 2 ppm \& Minimum root length observed with control
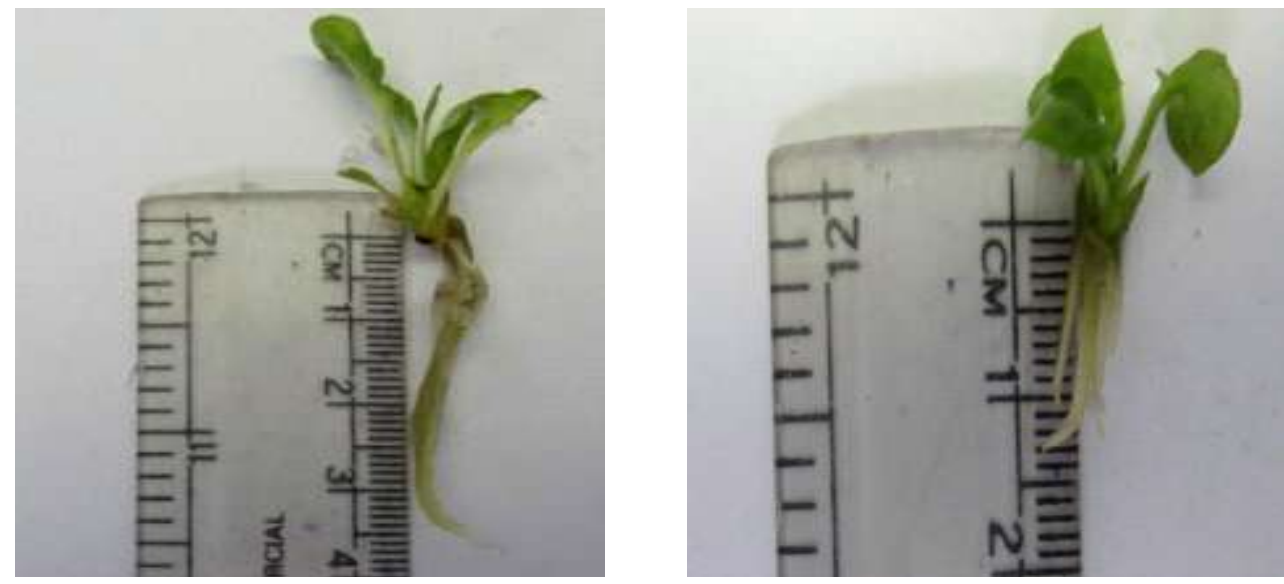
Unlikely to the above discussions, IBA at higher concentration (3 ppm) showed reduction in root growth with respect to number of days taken for rooting, number of roots per shoot and root length. In general, at higher concentrations it was found that auxin inhibited the rooting. Similar observations were made by Pierik (1987), who opined that auxin inhibits the adventitious and axillary bud formation at higher concentrations. In conclusion it could be suggested from the present study that for sterilization of gerbera, $0.1 \%$ mercuric chloride for 2 minutes is efficient and for shoot proliferation BAP at 4 mg per litre + IAA $0.3 \mathrm{mg}$ per litre was found best compared to other treatments. IBA at 2 mg per litre was found as the best rooting media.

\section{Rooting}

Induction of healthy root system from the regenerated shoots is an essential part for successful development of plantlets. Gerbera shoots obtained from multiplication process were further cultured in MS basal medium supplemented with different concentrations of IBA $(1.0,2.0$ and $3.0 \mathrm{ppm})$ and NAA $(0.5,1$, 1.5 and $2 \mathrm{ppm}$ ) for root induction.

Highest number of roots was obtained in the treatment MS supplemented with IBA compared to NAA. Within the different IBA concentrations, 2 ppm IBA resulted in producing more number of roots (4.73) and longer roots $(3.47 \mathrm{~cm})$. These findings were supported by Aswath and Choudhary (2001) with the similar outcome when cultured on MS medium containing $1.5 \mathrm{mg}$ per litre IBA. Next to IBA (2 ppm), NAA (2 ppm) registered maximum root length and number of roots.

It was found that auxins promoted root initiation and growth by inducing the cells to the pericycle and parenchyma to dedifferentiate and start initial cell division process (Celenza et al., 1995). Accumulation of auxin within the root tissues may cause an increase in the number of adventitious root formation (Laskowski et al., 1995). An increase in myelin basic protein (MBP) kinase activity in response to auxin treatment which provides a stimulus for mitogen activated protein kinase (MAPK) activation and initiated mitotic process which induces dedifferentiation of xylematic or parenchyma cells that acquired meristematic activity resulting in cell division and increased number of adventitious roots (Mockaitis and Howell, 2000).

\section{Acknowledgements}

The authors would like to thank the faculty at Department of Biotechnology and Department of Horticulture, College of Agriculture, Vijayapura for providing the facilities to carry out this research and University of Agricultural Sciences, Dharwad for providing all the facilities required to conduct the research.

\section{References}

Ajithkumar, K., Vijayan, P. and Nazeem, P. A., 2013. Callus induction and root regeneration in gerbera (Gerbera jamesonii). Asian J. Hort. 8(1): 374376.

Aswath, C. and Choudhary, M. L., 2001. Effect of cytokinins on proliferation of multiple shoots in gerbera (Gerbera jamesonii). Indian J. Hort. 58 (4): 383386.

Aswath, C. and Survey, N., 2004. An improved method for in vitro propagation of gerbera. J. Orn. Hort. 7(2): 141-146.

Barbosa, M. H. P., Pasqual, M., Pinto, J. E. B. P., Arello, E. F., Barros, D. and De, B., 1993. Effects of benzyl amino purine and indole-3-acetic acid on in vitro 
propagation of Gerbera jamesonii Bolus ex Hook cv. Appelbloesem. Pesquisa Agropecuaria Brasileira. 28(1): 15-19.

Celenza, J. L., Grisafi, P. L. and Fink, G. R., 1995. A pathway for lateral root formation in Arabidopsis thaliana. Genes Dev. 9: 2131-2142.

Das, P. and Singh, P. K.S., 1989. Gerbera. In: Bose T.K., Yadav L.P. (Eds), Commercial Flowers. Calcutta, Naya Prakash. 601-622.

Hempel, M., Petoz, W. B. and Tymoszuk, J., 1985. The influence of cytokinins on multiplication and subsequent rooting of gerbera in vitro. Acta Hort. 167: 301305.

Laskowski, M. J., Williams, M. E., Nasbaum, C. and Sussex, I. M., 1995. Formation of lateral root meristems is a two stage process. Dev. 121: 3303-3310.

Mandal, A. K. A. and Datta, S. K., 2002. Introduction of gerbera cultivation in Lucknow agro- climate through tissue culture of young flower head. Indian J. Biotechnol. 1(2): 212-214.

Mockaitis, K. and Howell, S. H., 2000. Auxin activated mitogenic activated protein kinase (MAPK) activation in roots of Arabidopsis seedlings. Plant J. 24: 785 796.

Murashige, T. and Skoog, F., 1962. A revised medium for rapid growth and bioassays with tobacco tissue culture. Physiol. Plant. 15: 473-497.

Murashige, T., Serpa, M. and Jones, J. B., 1974. Clonal multiplication of Gerbera through tissue culture. HortScience. 9(3): 175-180.

Nazari, F., Morteza, K. K., and Azadi, P.,
2016. A simple and efficient direct shoot organogenesis method using leafy petiole explants in Gerbera jamesonii 'Royal Soft Pink. Int. J. HortScience and Technol. 3(1): 51-58.

Panse, V.G. and Sukhatme, D.E.,.1986. In Statistical Methods for Agricultural Workers, $3^{\text {rd }}$ Ed., ICAR, New Delhi, India. 347.

Parthasarathy V.A., Nagaraju V., 1999. In vitro propagation in Gerbera jamesonii Bolus. Indian J. Hort. 56: 82- 85.

Pauling, L., 1955. College Chemistry. W. H. Freeman and Company, San Francisco, 578.

Peper H., Brandis A.V. and Dopke H., 1971. Clonal propagation of gerberas can be profitable. Result from Ahlem on the culture and clonal propagation of gerberas. Taspo, 105: 7.

Pierik, R. L. M., 1987. In-vitro culture of higher plants. Martinus Nijohff Publishers, Dordrecht. Netherlands. 344.

Pierik, R. L. M., Steegmans, H. H. M. and Marelis, J. J., 1973. Gerbera plantlets from in vitro cultivated capitulum explants. Sci. Hort. 1(1): 117-119.

Shailaja, M. R., Sashna, P., Chinjusha, V. and Nazeem, P. A., 2014. An efficient micropropagation protocol for Gerbera jamesonii Bolus from flower buds. Int. J. Plant Anim. Environ. Sci. 4(3): 641643.

Shailaja, V. P., Patil, S.S. and Ushakumari, M. K., 2004. Rapid clonal multiplication of Gerbera jamesonii Bolus through tissue culture. J. Orn. Hort. 7(3-4): 283-287.

\section{How to cite this article:}

Vijayalakshmi, C.L., P. Babu, A.N. Bagali, C.D. Soregaon and Ashwini H. Wadageri. 2019. Direct in vitro Regeneration of Gerbera (Gerbera jamesonii Bolus). Int.J.Curr.Microbiol.App.Sci. 8(01): 2610-2619. doi: https://doi.org/10.20546/ijcmas.2019.801.274 